\title{
Shape Inspection of Gear Prototypes Using Reverse Engineering Method
}

Josef Sedlak, Ales Polzer, Josef Chladil, Martin Slany, Ales Jaros

Department of Machining Technology, Institute of Manufacturing Technology, Faculty of Mechanical Engineering, Brno University of Technology, Technická 2896/2, Brno 616 69, Czech Republic. E-mail: sedlak@fme.vutbr.cz, polzer@fme.vutbr.cz, chladil@fme.vutbr.cz, slany.m@fme.vutbr.cz, jaros.a@fme.vutbr.cz

Reverse engineering is a technology that enables acceleration of data collecting for CAD, CAM, CAE systems, which also means shortening time of development, construction and components production. It is a transfer process of a physical component to a digital format. Generally, the technology of reverse engineering means a conversion of analogue data to digital data that are further processed. Every single industry branch rising their requirements on accuracy, dimension, quality, etc. Therefore, digitisation is applied in many production fields such as an automotive industry, aircraft or shipping, medicine, industrial design, design, etc.

An article deals with an analysis of prototype models of gears in various stages of production. The realized inspection of a shape of prototype gears lied in uploading of a digitised referential CAD model (the gear after heat treatment and machining), subsequent setting up of digitised prototype gears (the gear after the machining, gear after heat treatment) in respect of this referential CAD model, a control of their dimensions and forming a colour map of deviations in chosen points.

Keywords: Gears, Prototype Models, Digitisation, Component Inspection, 3D Scanner, Reverse Engineering, Technology

\section{Acknowledgement}

This article was supported and co-financed from a specific research FSI-S-16-3717 called "Research in Field of Modern Production Technologies for Specific Applications”.

\section{References}

[1] PÍŠKA, M. a kolektiv. (2009). Speciální technologie obrábění. CERM 1. vyd. 246 s. 2009. ISBN 978-80-2144025-8.

[2] NAVRÁTIL R. (2000). Reverse Engineering v praxi. [online]. Červen 2000 [vid. 2017-02-20]. Dostupné z: http://robo.hyperlink.cz.

[3] SEDLÁK, J. (2008). Moderní technologie reverzního inženýrství - využití 3D skenerů. Technik. 2008, roč. XVI, č. 3, s. 38-39. ISSN 1210-616X.

[4] SEDLÁK, J. (2008). Technologie výroby prototypů s podporou reverzního inženýrství a CAD/CAM: Disertační práce. Brno: Vysoké učení technické v Brně, Fakulta strojního inženýrství, Ústav strojírenské technologie, 2008. 104 s, 11 př́loh. Vedoucí disertační práce doc. Ing. Miroslav PÍŠKA, CSc.

[5] ZOUHAR, J., PÍŠA, Z., SEDLÁK, J., SEDLÁČEK, J. (2007). Produktivní obrábění s využitím metod reverzního inženýrství. In Sborník odborné konference „Frézováni IV“. Brno: VUT-FSI, Ústav strojírenské technologie ve spolupráci s PRAMET TOOLS, s.r.o. Šumperk a ZPS Frézovací nástroje, a.s., Zlín, 31.1.2007. s. 189-196. ISBN 80-214-3239-X.

[6] RAJA, V., FERNANDES, K. J. (2008). Reverse engineering: an industrial perspective. London: Springer, c2008. ISBN 978-1-84628-855-5.

[7] SEDLAK, J., PROCHAZKOVA, J. (2007). Direct B- Spline Interpolation of CNC Tool Trace From Cloadpoints. Manufacturing TECHNOLOGY, 2007, Vol. 7, No. 1, p. 66-71. ISSN 1213-2489.

[8] SEDLÁK, J., PROCHÁZKOVA, J. (2007). Direct B- Spline Interpolation of CNC Tool Trace From Cloadpoints. Strojírenská technologie, 2007, Vol. 12, No. 2, p. 24-28. ISSN 1211-4162.

[9] STYLIANOU, G., FARIN, G. (2003). Crest lines extraction from 3D triangulated meshes. In: Hierarchical and geometrical methods in scientific visualization. 2003. p. 69-81.

[10] WEBER, Ch., HAHMANN, S., HAGEN, H. (2010). Methods for feature detection in point cloud. In: Visualization of Large and Unstructured Data Sets-IRTG Workshop. 2010. p. 90-99.

[11] PIERACCINI, M.,GUIDI, G., ATZENI, C. (2001). 3D digitizing of cultural heritage, Journal of Cultural Heritage 2 (2001) p. 63-70. [online]. [seen 2017-03-12]. Available at: http://www.sciencedirect.com/science/article/pii/S1296207401011086. 
[12] 3D měreni MAPV 2009. [online]. 2009 [vid. 2017-02-20]. Dostupné z: http://www.uamt.feec.vutbr.cz/vision/TEACHING/MAPV/08\%20-\%203D\%20mereni.pdf.

[13] 3D Imaging with NI LabVIEW. National Instruments. [online]. 2012 [seen 2017-03-15]. Available at: http://www.ni.com/white-paper/14103/en.

[14] MCAE SYSTEMS, s.r.o., Kuřim, ČR. 3D měření, inspekce a skenování. [online]. [vid. 2017-04-05]. Dostupné z: $\mathrm{http} / / / \mathrm{www} . \mathrm{mcae} . \mathrm{cz} / \mathrm{cs} /$ sluzby/3d-mereni-inspekce-a-skenovani/.

[15] GOM GmbH, Schmitzstraße, Germany. Precise Industrial 3D Metrology. [online]. [seen 2017-03-07]. Available at: http://www.gom.com/3d-software/gom-inspect.html.

[16] FRVŠ, Financovaný projekt 1393/2013 - A/a, Prostorový skener pro výuku reverzního inženýrství (2013, FRVŠ). Hlavní řešitel: prof. Ing. Václav Píštěk, DrSc.

[17] Inspekce tvaru součásti. [online]. [vid. 2017-02-15]. Dostupné http://www.iae.fme.vutbr.cz/userfiles/ramik/files/Studium/Podklady\%20ke\%20studiu/3D\%20skenov\%C3\%A1n $\%$ C3\%AD/E-learning-Inspekce\%20tvaru\%20soucasti.pdf.

[18] ZETEK, M., ZETKOVA, I. (2017). Influence of the Workpice Quality on the Cutting Tool Life when Gear Wheel are Machined. Manufacturing Technology, 2017, Vol. 17, No. 1, p. 121-125. ISSN 1213-2489.

[19] JIROUS, S., FRANA, K. (2015). Pressure Analysis on the Surface Gearing Investigated by Numerical Simulation of Oil Flow in the Tooth Wheel Gap. Manufacturing Technology, 2015, Vol. 15, No. 5, p. 850-853. ISSN 12132489.

[20] SEDLÁK, J., POLZER, A., SLIWKOVÁ, P. (2016). Digitalizace prototypů ozubených kol pomoci optického skeneru ATOS Compact Scan 2M. Brno: 2016. s. 1-24. 